\title{
Diseño, construcción y automatización de una descremadora de leche para la alimentación en terneras Holstein mestizas
}

Design, construction and automation of a milk skimmer for feeding in holstein mestizo calves

\author{
María Alexandra Ramírez Orta. ${ }^{1}$, Gabriela Katherine Rosero Guerra. ${ }^{2}$, Byron Fernando \\ Castillo Parra. ${ }^{3}$ \& José Vicente Trujillo Villacis. ${ }^{4}$
}

\begin{abstract}
.
DOI: $\underline{\text { https://doi.org/10.33262/concienciadigital.v3i3.1311 }}$

A prototype of milk skimming machine was designed, built and automated, in order to provide skim milk to the calves, in the hacienda la Maga located in the Cascarillas Precinct, Sibambe Parish, Canton Alausí, Chimborazo Province. We evaluate the use of three liquid diets: with skim milk, whole milk and milk substitute for feeding in Holstein mongrel calves in the growth stage. In the experimental test, we used a total of 9 calves of two months of age weighing between 60 at 80 kilos, we evaluated three treatments with three repetitions, we used a completely random block design. The results showed us that the skimmer machine prototype achieved $90 \%$ efficiency, obtaining 1 liter of milk per 1 liter of milk 360 seconds, in the calves, three were no significant differences between the treatments, they gained average weights in the milk descrem of 27.32 kilograms, whole milk of 26,00 kilograms and substitute milk of 24,67 kilograms, in the 60 days with a presence of diarrhea of $0,0 \%$ in the three treatments. The determination of costs by treatment it was $\$ 1111,18$ for skim milk, $\$ 1059.40$ for whole milk and $\$ 1024,50$ for milk substitute. We concluded that the use of skim milk improves weight gain in Holstein mongrel calves, and economic activity of the herd rancher. We recommend using
\end{abstract}

\footnotetext{
${ }^{1}$ Hacienda la Maga, Chimborazo, Ecuador, marii_girlbright@outlook.es

${ }^{2}$ Hacienda la Maga, Chimborazo, Ecuador, gk_rg@hotmail.com

${ }^{3}$ Escuela Superior Politécnica de Chimborazo, Faculta de Ciencias Pecuarias, Chimborazo, Ecuador, byron.castillo@espoch.edu.ec

${ }^{4}$ Escuela Superior Politécnica de Chimborazo, Faculta de Ciencias Pecuarias, Chimborazo, Ecuador, jose.trujillo@espoch.edu.ec
} 
this prototype machinery to obtain skim milk and provide claves with a liquid diet, demonstrating efficiency and economy for the dairy producer.

Keywords: skimmer, performance, crossbred Holstein, weight gain.

\section{Resumen.}

En la Hacienda la Maga ubicada en el Recinto Cascarillas, Parroquia de Sibambe, Cantón Alausí, Provincia de Chimborazo, se diseñó, construyó y automatizó un prototipo de máquina descremadora de leche, el mismo que se utilizó para descremar, con el fin de suministrar leche descremada a las terneras. Se evaluó la utilización de tres dietas liquidas: con leche descremada, leche entera y sustituto de leche para la alimentación en terneras Holstein mestizas en la etapa de crecimiento. Se utilizó un total de 9 terneras de dos meses de edad con un peso entre 60 a 80 kilos, considerando que cada ternera es una unidad experimental, se valoró tres tratamientos con tres repeticiones, empleando un diseño de bloques completamente al azar (DBCA). Los resultados obtenidos demostraron que el prototipo de máquina descremadora alcanzó un $90 \%$ de eficiencia, obteniendo por cada 10 litros de leche 1 litro de crema en 360 segundos, en la prueba experimental en las terneras, no existieron diferencias significativas entre los tratamientos, puesto que alcanzaron ganancias de pesos promedios en leche descremada de 27,33 Kilos, leche entera de 26,00 kilos y sustituto de leche de 24,67 kilos, hasta los 60 días, con una presencia de diarreas del $0,0 \%$ en los tres tratamientos. La determinación de costos por tratamiento fue de $\$ 34,12$ para leche descremada, $\$ 22,40$ para leche entera y $\$ 25,50$ para sustituto de leche. Se recomienda utilizar este prototipo de maquinaria para obtener leche descremada y brindar a las terneras una dieta líquida de calidad, ya que ha demostrado eficiencia y economía para el productor.

Palabras clave: descremadora, rendimiento, Holstein mestizas, ganancia de peso.

\section{Introducción.}

Los síndromes digestivos constituyen los problemas de salud más frecuentemente observados en las crianzas de terneras (Waltner-Toews y col., 1986; Lorenz y col., 2011). Estos cuadros patológicos, afectan sensiblemente la supervivencia y tasa de crecimiento (Moran, 2002; Lorenz y col., 2011). Por ello, la respuesta que se obtiene en la crianza de terneras, guarda estrecha relación con el tipo y cantidad de alimento lácteo ofrecido, (Huber, J., 1984).

En bovinos uno de los inconvenientes más relevantes son los trastornos digestivos como diarreas, especialmente suceden en mayor porcentaje en animales hasta dos meses de edad, en algunos casos por agentes patológicos microbianos o por exceso de grasa en la leche y la temperatura de la misma al ser suministrada a los terneros, esto ocasiona grandes pérdidas económicas al productor, esto se debe a que se enferman y no ganan peso, este déficit se verá reflejado en el rendimiento productivo durante la vida del 
animal. La diarrea neonatal en terneros se caracteriza por la aparición de heces líquidas o acuosas de una forma repentina y aguda. Se manifiesta en un 10-35\% de los terneros lactantes y causa más del 50\% de las bajas antes del destete. La diarrea provoca apatía, así como una pérdida gradual del apetito y del crecimiento, llegando a disminuir la ganancia media diaria hasta 0,03K, (MAINAU, E., 2013).

En el racho la "Maga" se presentan a menudo casos de trastornos digestivos en los terneros especialmente presencia de diarreas esto influye en que los animales no alcanzan una adecuada ganancia de peso a lo largo de su etapa de engorde, esto implica a su vez que estos animales cuando entran en etapa de producción no alcanzan niveles satisfactorios; todo esto repercute en el aspecto económico del rancho ya que los beneficios resultantes no son los esperados y a un futuro complicaría la sostenibilidad del rancho debido que el rubro obtenido por la producción de leche y venta de animales es uno de los de mayor impacto en la economía del mismo. Esta no es una realidad que vive únicamente el Rancho la manga ya que consultando con las personas del territorio este problema es común en la mayoría de productores del sector, generando este problema un impacto económico en el sector.

Por dichas razones, en un futuro no existirá animales de remplazo y la explotación ganadera se verá en la necesidad de adquirir animales de otras explotaciones ganaderas, es por ello que se ha considerado la necesidad de crear un prototipo de máquina descremadora para brindar un alimento de calidad a los terneros/as, por ende al alimentarlos con leche descremada ganarán más peso optimizando de esta manera su comportamiento productivo con el fin de evitar problemas en la vida productiva del animal.

Una descremadora es un equipo separador centrífugo, utilizado para la disgregación de las dos fases que contiene la leche líquida entera, simultáneamente ambas fracciones quedan liberadas de impurezas y contaminantes (Valbuena et al., 2008).

En muchos casos la leche es primeramente clarificada a través de una centrífuga en la recepción para eliminar las impurezas. Si las condiciones del proceso son favorables, es también posible obtener una reducción eficiente en la cantidad de leucocitos y bacterias. El clarificador de leche puede operar con leche fría o caliente, sin embargo, una temperatura más alta aumenta la eficiencia de clarificación (Banda et al., 2010,).

La descremadora en la actualidad es considerada como una máquina eficiente dentro de la industria láctea, ya que este equipo, permite desnatar y mantener la temperatura de la leche mediante procesos de centrifugaciones y estas pueden dar un contenido de grasa residual en la misma.

Con este tipo de leche descremada de características nutritivamente recomendables, es posible brindar como fuente de alimentación a los terneros, ya que ayudará al becerro a evitar problemas gastrointestinales y por ende le permitirá adquirir una mayor ganancia 
de peso para posteriormente en un futuro obtener un buen comportamiento productivo durante la vida del animal.

Por otro lado, proporciona la oportunidad de contar con la crema la cual es posible preparar una variedad de productos y de esta manera obtener réditos económicos con la venta de este subproducto.

Con ello se considera implementar un prototipo de máquina portátil que descreme la leche descremada que se va a suministrar a los becerros en los potreros, esta máquina además de descremar garantizará que el producto a suministrar mantenga una temperatura adecuada para el consumo de los terneros, para lo cual tendrá incorporado un sistema de calentamiento, ya que es una máquina prototipo la capacidad de leche a descremar por parada es de 10 litros, suficiente para la alimentación de los terneros utilizados en la experimentación; esta descremadora se construirá con materiales de alta calidad para garantizar una adecuada inocuidad del producto a suministrar como alimento, con todos estos criterios de diseño se espera que los terneros alimentados con la leche descremada disminuirán los problemas de trastornos gastrointestinales del organismo del animal, lo que conllevará a una mejora en la ganancia de peso. Hay que tener en cuenta que siempre se debe llevar cabo normas de higiene adecuadas al momento de suministrar la leche descremada, entera y sustituto.

Esta máquina portátil sirvió para solucionar el problema de diarreas y la ganancia de peso en las terneras de remplazo.

La nutrición de la ternera lactante es crítica durante los primeros 30 a 60 días de vida, la fisiología digestiva de la ternera es como la de un animal monogástrico, por tal razón su estómago no está en capacidad de digerir alimentos fibrosos como los pastos y forrajes. La alimentación del ternero joven se realiza mediante métodos de alimentación, los que se esquematizan en cinco grupos: vaca nodriza, leche entera, subproductos de leche, cantidades limitadas de leche entera, sustituto de leche. Los dos primeros son más usuales, pero más caros. Los dos últimos necesitan un mejor manejo. Todos ellos pueden descomponerse en un primer período de alimentación líquida o periodo de "pre-destete" y en un segundo período de alimentación seca o post-destete" (Plaza et al., 2009).

Por lo citado anteriormente, en la presente investigación se plantearon los siguientes objetivos:

- Diseñar, construir y automatizar una descremadora de leche bovina con materiales de alta resistencia a la corrosión y oxidación.

- Determinar la eficiencia del equipo y rendimiento de la descremadora de leche bovina, así como establecer las normas básicas para el adecuado mantenimiento del equipo.

- Valorar los costos de construcción, instalación y funcionamiento. 
- Evaluar tres tipos de suplementación de leche en la alimentación en terneras.

- Determinar el costo por tratamiento.

\section{Metodología.}

La investigación se realizó en el Rancho "La Maga" ubicado en el Recinto Cascarillas, Parroquia de Sibambe, Cantón Alausí, Provincia de Chimborazo. Situado en la vía Pepinales- Remijòn. La investigación tuvo una duración de 90 días. En la tabla 1 se específica las condiciones meteorológicas de la Parroquia Sibambe.

Tabla 1: Condiciones Meteorológicas de la Parroquia Sibambe

\begin{tabular}{cccc}
\hline \multicolumn{4}{c}{ Parámetro Promedio } \\
\hline Temperatura & Precipitación & Viento & Altitud \\
$1116^{\circ} \mathrm{C}$ & $250-500 \mathrm{~mm}$ & $20-25 \mathrm{~km} / \mathrm{h}$ & 2460 m.s.n.m. \\
\hline
\end{tabular}

Fuente: Gobierno Autónomo descentralizado de la parroquia de Sibambe, (2018).

Las unidades experimentales estuvieron conformadas por 9 terneras Holstein mestizas de 6 a 10 semanas de edad con un peso entre 50 a $80 \mathrm{~kg}$, distribuidas en tres tratamientos con 3 repeticiones por tratamiento.

Unidad de apoyo en el Rancho "La Maga" ubicado en el Recinto Cascarillas

\section{Tratamiento y diseño experimental}

Esta investigación se fundamentó en el estudio de procesos para el diseño, construcción y automatización de la descremadora de leche para el Rancho "La Maga". Una vez instalado el equipo se realizó una prueba piloto para verificar el funcionamiento correcto del prototipo.

Se utilizó está máquina para extraer la grasa de la leche, con el fin de suministrar leche descremada a las terneras. En esta investigación se utilizó tres tratamientos: leche descremada (T1), leche entera (T2), sustituto de leche (T3); con tres repeticiones cada uno, los cuales fueron analizados bajo un diseño de bloques completamente al azar (DBCA).

\section{A. Esquema del Experimento}

En la tabla 2, se observa el esquema del experimento. 
Tabla 2: Esquema del Experimento

\begin{tabular}{ccccc}
\hline Tratamientos (T) & Código & Repeticiones. & T. U. E & Animales/ T \\
\hline $\begin{array}{c}\text { Leche } \\
\text { descremada. }\end{array}$ & T1 & 3 & 1 & 3 \\
Leche entera. & T2 & 3 & 1 & 3 \\
Sustituto de leche. & T3 & 3 & 1 & 3 \\
TOTAL. & & & & 9 \\
\hline
\end{tabular}

Fuente: Elaboración propia.

\section{B. Mediciones experimentales}

Mediciones técnicas para la descremadora de leche:

- Eficiencia de la máquina descremadora.

Mediciones experimentales para los animales:

- Ganancia de peso (g)

- Presencia de diarreas \%

\section{Análisis estadísticos y pruebas de significancia}

En la presente investigación los datos obtenidos se evaluaron mediante un análisis de varianza (ADEVA), por medio de un paquete estadístico Statistical Package for the Social Sciences (SPSS 2013), se realizó la separación de medias con la Prueba Estadística de Tukey $\leq 0,05 \%$.

\section{Esquema del ADEVA}

En la tabla 3 se observa el Esquema del ADEVA.

Tabla 3: Esquema del Experimento

\begin{tabular}{cc}
\hline Fuentes de variación & Grados de Libertad \\
\hline Total & 8 \\
Tratamientos & 2 \\
Bloques & 2 \\
Error & 4 \\
\hline
\end{tabular}


Fuente: Elaboración propia.

\section{E. Procedimiento experimental}

La presente investigación se desarrolló en dos etapas: 1. Diseño, construcción y automatización de la máquina descremadora de leche; 2. Prueba experimental en 9 terneras Holstein Mestizas, para determinar el mejor tratamiento entre T1, T2 y T3.

\section{F. Diseño, Construcción y Automatización de la máquina descremadora}

\section{Diseño}

La elaboración de planos de la máquina fueron el bosquejo que permitió ejecutar la construcción de la misma, la idea plasmada en el diseño tuvo como objetivo crear una máquina que sea transportable de manera fácil en terrenos a desnivel, elaborada de materiales inoxidables para que soporte las variaciones del clima y se acople a las necesidades del productor, para así proporcionar a las terneras leche descremada a una temperatura ideal de 37,5 grados centígrados.

\section{Construcción.}

Se realizó la construcción de un carrito transportador con materiales de acero inoxidable, al mismo que se acopló la descremadora, la planta de luz y finalmente dispone de un tablero de control que regula la temperatura de la leche descremada.

\section{Materiales}

Estructura: dos tubos cuadrados de $\left(1 \frac{1 / 4}{4}\right.$ 1,5) centímetros de espesor.

Acabados externos: plancha de acero inoxidable AISI 430 satinado de 0,70 milímetros de espesor.

Reverbero: eléctrico de 110 voltios.

Recipiente receptor de leche descremada: $1 / 4$ de plancha de acero inoxidable AISI 304 grado alimenticio con capacidad de 10 litros y una llave inferior de acero alimenticio, que permite la salida de la leche descremada.

Planta de luz: 250 voltios, requerida para arrancar un motor de 0,75 hourse power de marca SHINERAY.

Ruedas: 4 ruedas de 4 x 4 de 26 centímetros de diámetro.

Descremadora: Marca SICH. 


\section{Ensamblaje}

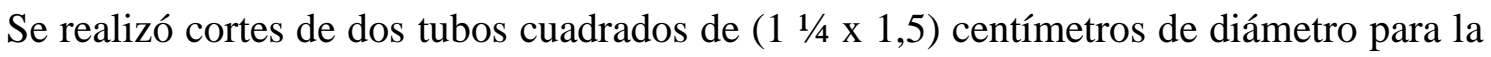
estructura y soporte del carrito transportador.

Se cortó la plancha de acero inoxidable AISI 430 satinado con espesor de 0.7 milímetros, para armar la estructura externa.

Se soldó las planchas cortadas a los tubos para armar la estructura del carrito.

Posteriormente se dobló una plancha de acero inoxidable AISI 304 grado alimenticio en forma cilíndrica para crear así el recipiente receptor de la leche descremada, finalmente se realizó una perforación en la parte inferior del mismo y se colocó una llave de 1/8 pulgadas que permita la salida de la leche, este bidón, se ubicó sobre un reverbero eléctrico.

Una vez soldado el armazón del carrito, se ubicó las ruedas 4 x 4 en la parte inferior del carrito.

La descremadora SICH se ubicó en la parte delantera, de tal manera que se encuentre fija y nivelada.

En la parte posterior a la descremadora se encuentra la planta de luz a gasolina marca SHIRENAY, ubicada sobre una plancha de madera y equilibrada de tal manera que esté bien sujeta y no se desnivele con el movimiento de la máquina al ser transportada de potrero a potrero.

En la parte posterior del carrito se soldó un pedestal en el cual se colocó el gabinete modular de automatización.

\section{Automatización}

El gabinete modular tiene una dimensión de 40 centímetros de largo x 40 centímetros de ancho, con una profundidad de 20 centímetros, el cual consta de botones de encendido, apagado, pulsador de emergencia, luz piloto de descremada, una perilla (controlador de temperatura - descremado) y una pantalla de lectura de temperatura en grados centígrados.

\section{Funcionamiento}

En el tablero de control se encuentran botones de encendido (verde), apagado (rojo), pulsador de emergencia (rojo), luz piloto de descremado (azul), una perilla (descremada - temperatura) y una pantalla de lectura de temperatura en grados centígrados.

Al momento de iniciar el proceso de descremado, la luz azul se enciende e indica que dicha actividad está ejecutando la máquina, al finalizar, se calienta la leche descremada, 
ya que, en el proceso de centrifugación, la temperatura del fluido baja e inmediatamente esta luz se apaga.

El reverbero se enciende de manera automática, de inmediato, se refleja en la pantalla ubicada en la parte superior derecha del tablero la temperatura que va ascendiendo la leche, esto ocurre, ya que en el bidón receptor se encuentra un sensor de temperatura; al llegar a 38 grados centígrados se apaga concluyendo la actividad total de la máquina.

\section{G. Metodología de evaluación}

\section{Descripción mediciones experimentales de la máquina}

Para determinar la eficiencia de la máquina descremadora, se midió con un cronómetro el tiempo empleado en segundos para descremar 10 litros de leche; y posteriormente se calculó con la ecuación 1 .

Eficiencia de la máquina

\section{Descripción de las mediciones experimentales en las terneras}

Antes de iniciar el trabajo de investigación se tomó muestras de las excretas a las nueve terneras Holstein mestizas para el análisis coproparasitario. Mediante el método de flotación y sedimentación se determinó cualitativamente los parásitos gastro intestinales presentes en los animales.

Con lo obtenido se procedió a desparasitar con albendazol, con dosis de $1 \mathrm{ml} / \mathrm{kg}$ de peso, la desparasitación se realizó con $\mathrm{AD} 3 \mathrm{E} 1 \mathrm{ml} / \mathrm{kg}$ de peso, esta es una terapia complementaria luego de cada desparasitación.

En el rancho la Maga se realizan desparasitaciones y vitaminizaciones cada 3 o 4 meses.

\section{Ganancia de Peso}

Para tomar la ganancia de peso en las terneras, los animales eran trasladados a una manga, éstos ingresaban por la parte posterior de la misma, al tomar una posición correcta: cabeza alzada hacia adelante, manos y patas alineados formando un ángulo de 90 grados al cuerpo, con la ayuda de una cinta bovinométrica que bordea el tronco detrás de las manos, a la altura de la cruz, se procedía a tomar lectura de los pesos cada 5 días.

\section{Tratamiento con Leche Descremada}

Se suministró seis litros de leche descremada a cada ternera en dos tomas: 3 litros de leche en la mañana y 3 litros de leche en la tarde, a una temperatura de 37,5 grados centígrados.

Tratamiento con Leche Entera 
Se suministró 3 litros de leche en la mañana y 3 litros de leche en la tarde a cada ternera, a una temperatura de 37,5 grados centígrados.

Tratamiento con Sustituto de leche.

Para preparar este tratamiento, se procedió a pesar 100 gramos de polvo de leche sustituta por litro de agua, es decir, 900 gramos se disolvían en 9 litros de agua a una temperatura de 50 grados centígrados, con la finalidad que se disuelva de manera correcta y no pierda las propiedades nutricionales.

Se suministró 3 litros de leche en la mañana y 3 litros de leche en la tarde a cada ternera, a una temperatura de 37,5 grados centígrados.

A todas las terneras de esta investigación, se les procedía a suministrar 400 gr de balanceado inicial de terneras a las $11 \mathrm{am}$.

El forraje verde, agua y sales minerales fueron consumidos a voluntad (at libitum).

\section{Presencia de diarreas}

Para determinar la presencia de diarreas, se observaba alrededor de cada animal que las excretas no sean liquidas y mal olientes.

\section{Resultados}

\section{Máquina}

\section{Eficiencia de la maquinaria}

Eficiencia de la máquina

Eficiencia de la máquina $(\%)=90 \%$

Figura 1: En tres dimensiones la maquina descremadora de leche con sus respectivos partes.

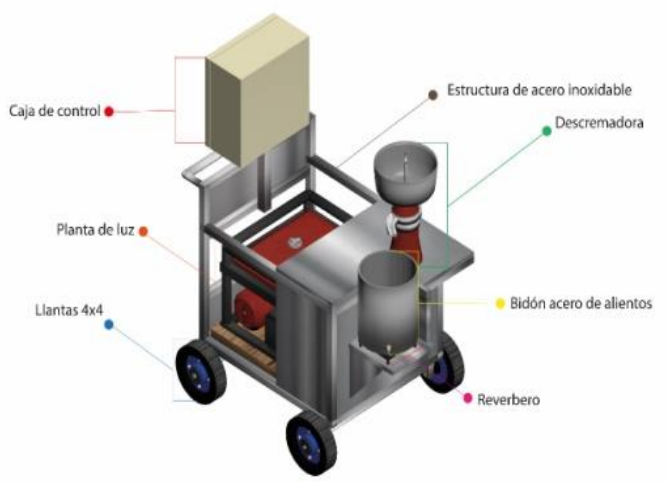

Fuente: Elaboración propia. 
Figura 2: En tres dimensiones la vista lateral de la máquina descremadora de leche.

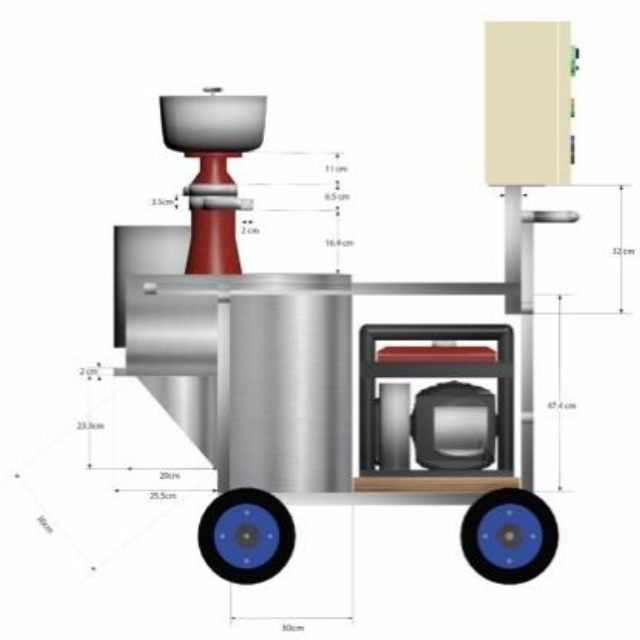

Fuente: Elaboración propia.

Los 10 litros de leche entera ingresados en la tolva, luego del proceso de centrifugación se disgregan en dos partes: 9 litros de leche descremada y 1 litro de crema en un intervalo de tiempo de 360 segundos.

La temperatura inicial de la leche entera oscila en 34 grados centígrados al momento de ingresar a la tolva para ser descremada, la temperatura disminuye por el proceso de centrifugación a 31 grados centígrados, empleando un tiempo de 804 segundos en incrementar 6,5 grados centígrados, temperatura ideal $\left(37,5^{\circ} \mathrm{C}\right)$ para suministrar este tratamiento a las terneras.

\section{Capacidad}

La capacidad de la tolva de la descremadora fue de 10 litros, debido a que luego del proceso de centrifugación se obtiene 9 litros de leche descremada, cantidad necesaria para suministrar a las tres unidades experimentales del tratamiento con leche descremada (T1)

\section{Costo total de la maquinaria}

En la tabla 9 del capítulo 3, se detalla el costo total de la maquinaria.

Tabla 4. Costo Total de la Maquinaria

\begin{tabular}{cc}
\hline Detalle & Precio $\$$ \\
\hline $\begin{array}{c}\text { Construcción de la máquina } \\
\text { Automatización de la } \\
\text { máquina } \\
\text { TOTAL }\end{array}$ & $\$ 1720$ \\
\hline 6225,59 \\
\hline
\end{tabular}


Fuente: Elaboración propia.

El costo total de la máquina descremadora tuvo un costo de dos mil trescientos cuarenta y cinco dólares americanos y 59 centavos.

\section{B. Análisis de muestras}

En la tabla 5 detalla el cuadro resumen del análisis estadístico.

Tabla 5. Análisis Estadístico

\begin{tabular}{cccccc}
\hline Variables & T1 & T2 & T3 & E.E. & P-valor \\
\hline Peso inicial $(\mathrm{kg})$ & 61,67 & 62,00 & 62,00 & 1,07 & - \\
Peso final $(\mathrm{kg})$ & $89,00 \mathrm{a}$ & $88,00 \mathrm{a}$ & $86,67 \mathrm{a}$ & 1,61 & 0,66 \\
Ganancia de peso $(\mathrm{kg})$ & $27,33 \mathrm{a}$ & $26,00 \mathrm{a}$ & $24,67 \mathrm{a}$ & 0,75 & 0,15 \\
Diarreas $(\%)$ & 0 & 0 & 0 & & - \\
\hline
\end{tabular}

*E. E: Error Experimental, P-valor: Probabilidad, CV: Coeficiente de variación, G. peso: ganancia de peso

*E. E: Error Experimental, P-valor: Probabilidad, CV: Coeficiente de variación, G. peso: ganancia de peso

Fuente: Elaboración propia.

\section{Ganancia de peso (kilogramos)}

La ganancia de peso de las terneras Holstein Mestizas se tomó cada 5 días, utilizando una cinta bovino-métrica En la presente investigación los datos obtenidos se evaluaron mediante la separación de medias con la Prueba Estadística de Tukey $\geq 0,05$, reportando promedios para leche descremada (T1) de 27,33 kilogramos, leche entra (T2) 26,00 kilogramos y Sustituto de leche (T3) de 24,67 kilogramos, no se obtuvieron diferencias significativas entre los tratamientos.

\section{Diarreas (\%)}

Las diarreas bajaron en su totalidad en todos los tiramientos, debido a que se controló la temperatura de la dieta líquida, la cantidad, el horario y sanidad, estos parámetros son fundamentales al alimentar a terneras. 


\section{Resultados.}

\section{Ganancia de peso}

\section{Leche descremada}

La ganancia de peso suministrando leche descremada en terneras Holstein mestizas fue de 27,33 kg en los 60 días de investigación, es decir una ganancia diaria promedio de 455,5 gramos, al comparar con (Dechambre,1987), quien racionó 9 litros de leche descremada más 540 gramos de harina de yuca obtuvo una ganancia de peso de 54 a 59 kilos en 6 días ganado 833 gramos/día, superando a los datos obtenidos actualmente, esto se debe a la adición de harina de yuca, siendo este un producto netamente un carbohidrato.

(Phanor, 1991), en un grupo de terneras investigó durante 110 días suministrando una mezcla de 3 litros, $50 \%$ leche descremada y $50 \%$ suero de mantequilla, alcanzando una ganancia de peso en ese lapso de tiempo de 31 a 77 kilogramos, es decir, logrando conseguir incremento de 418 gramos/día, obteniendo resultados inferiores al comparar con los datos actuales, esto se debe que a pesar de que utilizó suero de mantequilla y leche descremada suministró menor cantidad del alimento a los animales.

(Batres, 1996), evaluó la utilización de harina de maíz como reconstituyente de leche descremada la cual fue empleada en alimentación de terneras, el experimento tuvo una duración de 90 días, para el desarrollo experimental se utilizaron 15 terneras de raza Holstein a los cinco días de edad. Los tratamientos evaluados fueron T1: 30 días de leche entera y 60 días de mezcla $50 \%$ de leche entera y 50\% de leche descremada más sustituto de leche a razón de 15.13 gramos por litro de leche, en el T2: 30 días de leche entera y 60 de leche descremada; y en el T3: 30 días de leche entera y 60 días de leche descremada reconstituida con 24.66 gramos de harina de maíz precocida por litro de leche, a todos los tratamientos se les ofreció libremente heno de pasto de estrella y en los primeros días concentrado a razón de $0.4 \mathrm{~kg}$ por ternera al día y los siguientes 60 días $2.5 \mathrm{~kg}$ de concentrado diario por ternera. Las ganancias de peso diarias fueron: $\mathrm{T} 1=680 \mathrm{~g}, \mathrm{~T} 2=660$ $\mathrm{kg}$, y el T3=910 kg; los resultados obtenidos son superiores a los de la presente investigación debido a que se utilizó concentrado en la dieta diaria de las terneras, así como un sustituto de leche en el T1 y leche reconstituida con harina de maíz en el T3.

\section{Leche entera}

La ganancia de peso suministrando leche entera durante 60 días fue de 26,00 Kg, es decir una ganancia de peso promedio de 433, 33 gramos/día, estos resultados fueron inferiores a los datos obtenidos por (Balseca, S. y Barberena, R., 2017)., puesto que obtuvo una ganancia de peso de $444 \mathrm{~g}$ /día suministrando la misma cantidad de leche, mientras que aplicando un sistema intensivo obtuvo mayor ganancia de peso de 620 gramos/día, esto se debe a que dentro de este sistema de explotación se controla mejor las condiciones del hábitat del animal. 
(Plaza, J., Martínez, Y. y Ibalmea, R., 2008), utilizó tratamientos con leche entera en terneras Holstein x Cebú, suministrando 4litros dos veces al día, alcanzando una ganancia de 609 gramos/día desde los 31 días a los 60 días, los datos obtenidos son superiores a la investigación realizada actualmente, debido a que fueron criadas en cuneros por ende no desgastan energía y es ahorrada para el mantenimiento del animal.

\section{Sustituto de Leche}

La ganancia de peso suministrando sustituto de leche durante 60 días fue de $24,67 \mathrm{Kg}$, es decir una ganancia de peso promedio de 411,16 gramos/día, obteniendo resultados inferiores a los de (Vallejo, 1999), donde obtuvo una ganancia de peso de 448 g/día, debido a que utilizó una fuente de proteína no láctea en el sustituto lácteo, está fuente hidrolizada de pescado remplazó un 37,5\% de la proteína de origen lácteo.

(Plaza, J., Martínez, Y. y Ibalmea, R., 2008), utilizó tratamiento con sustito de leche (Maxicar + Relac) en terneras Holstein x Cebú suministrando 4litros, dos veces al día, obteniendo una ganancia de peso de 610 g/día desde los 31 días a los 60 días, logrando resultados superiores a la investigación realizada actualmente, debido a que fueron alimentadas por lacto remplazantes de alta calidad a base de solo proteína láctea y a la vez los animales permanecieron criadas en cuneros por ende la energía ahorrada es utilizada para el mantenimiento del mismo.

\section{Porcentaje de incidencia de diarrea}

Durante el trabajo realizado no se registraron incidencias de procesos diarreicos en los animales. Se registró un 0\% de incidencia de diarreas, debido a que la temperatura de la leche se controló a 37,5 grados centígrados, en cada toma, al analizar la investigación realizada por (Vallejos, 1999), con un grupo de terneras entre un mes y dos meses suministrando lacto reemplazante más una fuente proteica de origen animal obtuvo presencia de diarreas, aun controlando la temperatura y la dilución del sustituto, se le puede atribuir a la presencia de harina de pescado adicionada al lacto reemplazante, la cual no debió ser bien asimilada por los animales.

\section{Análisis Económico.}

Dentro de la estructura del análisis económico se consideraron; los egresos por los costos de producción en los grupos experimentales de terneras y los ingresos obtenidos con la cotización final de los animales, obteniendo una ganancia con leche descremada de $\$$ 34,12 , sustituto de leche de $\$ 25,50$ y leche entera de y $\$ 22,40$ dólares americanos.

De esta manera se demuestra que al emplear el tratamiento con leche descremada a las terneras se mejora la actividad económica, esto se debe a que la crema de leche extraído del producto descremado proporciona un ingreso económico superior frente a los otros tratamientos con leche entera y sustituto de leche. En la tabla 6 se detalla los ingresos y egresos de cada uno de los tres tratamientos investigados. 
Tabla 6. Análisis de Egresos e Ingresos

TRATAMIENTOS

CONCEPTO

(T1)

(T2)

(T3)

EGRESOS

Terneras

375,00

375,00

375,00

Dieta líquida

388,88

388,88

345,00

Alimento balanceado

35,00

35,00

35,00

Forraje verde

237,6

237,6

237,6

Desparasitantes y

Vitaminas

$1,00 \quad 1,00 \quad 1,00$

Mano de obra

27,00

22,00

27,00

Combustible

7,40

0

0

Gas

0

0

3,00

Depreciación de la maquinaria

$$
40,00
$$

0

0,90

TOTAL, EGRESOS

1111,88

1059,4

1024,5

\section{INGRESOS}

Crema de leche

96,00

0

0

Venta de terneras

1050,00

1050,00

1050,00

TOTAL, INGRESOS

1194

1050

1050

TOTAL, USD

34,12

22,40

25,50

Fuente: Elaboración propia.

\section{Conclusiones:}

- Se diseñó, construyó y automatizó un prototipo de máquina descremadora de leche, en la cual se obtuvo un $90 \%$ de eficiencia de la misma, obteniendo 9 litros de leche descremada en 360 segundos; es decir tiempos cortos de descremado de leche.

- Al utilizar esta máquina para obtener leche descremada y suministrar a las terneras, se obtiene una ganancia de peso estadísticamente no significativa en los tratamientos y al analizar los costos por tratamientos se obtiene un ingreso superior en leche descremada respecto a los tratamientos con leche entera y sustituto de leche. 
- El uso de leche descremada permite mejorar la ganancia de peso en terneras Holstein mestizas y además mejora la actividad económica del hato ganadero, evitando enfermedades en los animales.

- No hubo presencia de diarreas en cada uno de los tratamientos realizados, debido a que se controló la cantidad de leche exacta suministrada a los animales, el grado de la temperatura y el horario.

- En el análisis económico se puede evidenciar que muestra ganancias significativas en el precio de los animales al utiliza leche descremada, lo que permite al ganadero que realice o se vea como una opción viable la inversión en la máquina, y que pueda utilizar en su propiedad como una herramienta del diario vivir.

\section{Referencias bibliográficas:}

Balseca, S. y Barberena, R. (2017). Evaluación del sistema de crianza intensivo de terneras con leche entera y el sistema convencional con lacto reemplazador. Escuela Agrícola Panamericana.

Banda R., Evangelista V., Ruiz, G., Sandoval M., Rodríguez Ll., Valdivia C., Santiani A. (2010). Efecto de dilutores en base a tris, tes y leche descremada en la crio preservación de espermatozoides obtenidos del epidídimo de alpaca. Perú: Revista de Investigaciones Veterinarias del Perú, vol. 21, n (2) pp. 145-153.

Dechambre, W. (1987). Cría de terneras con leche desnatada y Harina de yuca. Boletín de Fomento. España 60(2) p. 60.

Huber, J. T., Silva, A. G., Campos, O. D., \& Mathieu, C. M. (1984). Influence of Feeding Different Amounts of Milk on Performance, Health, and Absorption Capability of Baby Calves1. Journal of dairy science, 67(12), 2957-2963.

Lorenz, I., Mee, J, F., Bernadette, E., More, S, J. (2011), Calf health form birth to weaning I. General aspect of disease prevention. IrishVet J, United States American, California, vol. 10, pp.1-8.

Mainau, e., temple, d., \& manteca, x. (2013). Aspectos de bienestar relacionados con la diarrea en terneros lactantes, pp 1-2.

Moran, J.(2002), Calf rearing: A practical guide. Land Links. CSIRO Melbourne. United States American, Kentuky vol. 2 p. 211.

Phanor, L. (1991). Utilización de leche descremada y suero de mantequilla en la crianza artificial de terneras lucerna. Colombia: Universidad Nacional de Colombia, pp. 126-131.

Plaza, J. (1986). Utilización del yogurt y lacto crema en alimentación de terneros. ACPA. Cuba., 1986, (Cuba), La Habana, vol. 8, n (4) p. 38.

Plaza, J., Martínez, Y. y Ibalmea, R. (2008). Efecto de la leche enteran y los remplazadores lecheros en el comportamiento de terneras de reposición“. Revista Cubana de Ciencia Agrícola. Cuba, La Habana, vol. 42, n (4) pp. 352-353. 
Plaza, J., Martínez, Y. y Ibalmea, R. (2009). Respuesta del uso eficiente del calostro en los terneros de una lechería. Revista Cubana de Ciencia Agrícola, Cuba, La Habana, vol. 43, $\mathrm{n}^{\circ}$ (1) pp. 15-18.

Plaza, J., Martínez, Y. y Ibalmea, R. (2009). Manejo del alimento fibroso en la alimentación de terneras de reposición. Revista Cubana de Ciencia Agrícola, Cuba, La Habana, vol. 43, n (1) pp. 19-22.

Waltner-Toews, D., Martin, S W., Meek, A H. (1986), Dairy calf management, morbidity and mortality in Ontario Holstein herds. PrevVet, Med, Inglaterra, vol. 4. Pp 103.

Valbuena, E., Barreiro, J., Sánchez, E., Castro, G., Kutchinskaya, V. y Briñez, W. (2018), Predicción del crecimiento de Lactococcuslactissubsp. lactis en leche descremada estéril en función a la temperatura. Revista Científic. España, Madrid, vol. 18, $\mathrm{n}^{\circ}$ (6) pp. 745-758.

Vallejo, F. (1999). Evaluación del uso de un sustituto lácteo con un hidrolizado de pescado como fuente de proteína para la crianza de terneras de reemplazo. Chile: Universidad Austral de Chile. Facultad de Ciencias Veterinarias. Instituto de Zootecnia. 1 - 15 . 


\section{PARA CITAR EL ARTÍCULO INDEXADO.}

Ramírez Orta, M. A., Rosero Guerra, G. K., Castillo Parra, B. F., \& Trujillo Villacis, J. V. (2020). Diseño, construcción y automatización de una descremadora de leche para la alimentación en terneras Holstein mestizas. ConcienciaDigital, 3(3), 275-292. https://doi.org/10.33262/concienciadigital.v3i3.1311

\section{LCiencia}

El artículo que se publica es de exclusiva responsabilidad de los autores y no necesariamente reflejan el pensamiento de la Revista Conciencia Digital.

El artículo queda en propiedad de la revista y, por tanto, su publicación parcial y/o total en otro medio tiene que ser autorizado por el director de la Revista Conciencia Digital.

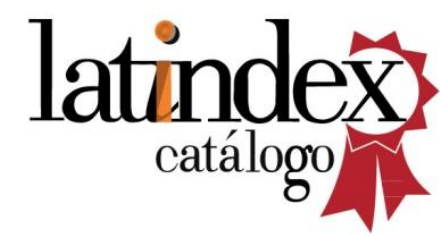

